\title{
Radiation treatment for WHO grade II and III meningiomas
}

\author{
Brian P. Walcott ${ }^{1}$, Brian V. Nahed ${ }^{1}$, Priscilla K. Brastianos ${ }^{2,3,4}$ and Jay S. Loeffler ${ }^{5}$ \\ 1 Department of Neurological Surgery, Massachusetts General Hospital, Harvard Medical School, Boston, MA, USA \\ 2 Department of Medicine, Massachusetts General Hospital, Harvard Medical School, Boston, MA, USA \\ ${ }^{3}$ Department of Medical Oncology, Dana-Farber Cancer Institute, Boston, MA, USA \\ ${ }^{4}$ Broad Institute of Massachusetts Institute of Technology, Harvard University, Boston, MA, USA \\ ${ }^{5}$ Department of Radiation Oncology, Massachusetts General Hospital, Harvard Medical School, Boston, MA, USA
}

Edited by:

Søren M. Bentzen, University of Wisconsin School of Medicine and Public Health, USA

Reviewed by:

Sean Collins, Georgetown University Hospital, USA

Jonathan P. S. Knisely, North Shore

University Hospital, USA

*Correspondence:

Brian P. Walcott, Department of Neurological Surgery, Massachusetts

General Hospital, Harvard Medical

School, 55 Fruit Street, White Building

Room 502, Boston, MA 02114, USA

e-mail:walcott.brian@

mgh.harvard.edu
The treatment of meningiomas is tailored to their histological grade. While World Health Organization (WHO) grade I lesions can be treated with either surgery or external beam radiation, WHO Grade II and III lesions often require a combination of the two modalities. For these high-grade lesions, conventional external beam radiation is delivered to either the residual tumor or the surgical resection margin. The optimal timing of radiation, either immediately following surgical resection or at the time of recurrence, is yet to be determined. Additionally, another method of radiation delivery, brachytherapy, can be administered locally at the time of surgery for recurrent lesions. Altogether, the complex nature of WHO grade II and III meningiomas requires careful treatment planning and delivery by a multidisciplinary team.

Keywords: meningioma, radiosurgery, proton therapy, surgery, brachytherapy
Meningiomas are classified morphologically by the World Health Organization (WHO) grading scheme into three categories (1). While most meningiomas are benign or grade I, the propensity of certain subtypes to recur following treatment creates a pathological course that can lead to a spectrum of malignant disease.

The goal of surgery is to safely resect the tumor and obtain a diagnosis and pathological grade. Subsequent radiation therapy depends on the extent of resection and pathological characteristics. Patients harboring either WHO grade II or III meningiomas have higher recurrence rates, varying between $29-52$ and 50$94 \%$ respectively (2-9). This may be due in part to parenchymal invasion or the aggressiveness of residual tumor cells. Higher recurrence rates correlate with decreased overall survival (6). The role of surgery alone is typically inadequate given the high local recurrence rate. Preliminary observational studies have demonstrated that radiation improves recurrence rates and overall survival in these cases (10-12). Therefore, for grade II and grade III lesions, radiation is often an integral part of any treatment regimen. Radiation is delivered via an external beam source or via radioactive seeds implanted locally during a surgical procedure (brachytherapy).

\section{EXTERNAL BEAM RADIATION}

Several types of external beam radiation exist, including newer technologies and delivery techniques such as photon based stereotactic radiosurgery (13-16), hypo-fractionated radiation therapy $(17,18)$, and hadron therapy (e.g., proton radiation) (19-22). Treatment plans may be devised to target the remaining lesional tissue following subtotal resection, or the resection cavity plus a margin of approximately $1 \mathrm{~cm}$ following gross total resection of higher grade tumors. Radiation treatment planning requires balancing the dose and volume delivered for a clinical benefit with the potential toxicities. Radiation necrosis (22), exacerbation of peritumoral edema (23-25), optic neuropathy (26), cranial nerve palsy (27), and wound complications are the principle complications seen following radiation therapy of intracranial meningiomas.

While the literature is rich with studies on meningiomas, there is little outcome data available on radiation treatment for WHO grade II and III meningiomas. All current evidence stems from retrospective case series, which have been subject to evolution in treatment methodologies and changes in the grading scheme over time $(1,28)$. Nonetheless, radiation therapy, typically administered as an immediate adjuvant dose (alternatively at the time of recurrence) is common for the treatment of these lesions. It should be noted that since there are no randomized trials, controversy and differential practice patterns exist with several aspects of radiation therapy including timing following resection, and best modality of radiation therapy.

Based upon retrospective data, there is a trend toward improved outcomes with immediate post-operative radiation following gross total resection with WHO grade II and III meningiomas. A single center series analyzed outcomes in 108 patients who underwent a gross total resection (Simpson grade I) for an atypical meningioma (2). In this series, the vast majority of patients (100 patients) were treated with surgery alone, while only 8 patients received immediate adjuvant radiation therapy (stereotactic fractionated radiotherapy) to an approximately $1 \mathrm{~cm}$ margin around the resection cavity. Overall, 30 patients recurred after gross total resection without adjuvant radiation therapy, whereas none of the 8 patients who received adjuvant radiation therapy recurred. Despite this, rates of recurrence between post-operative irradiated 


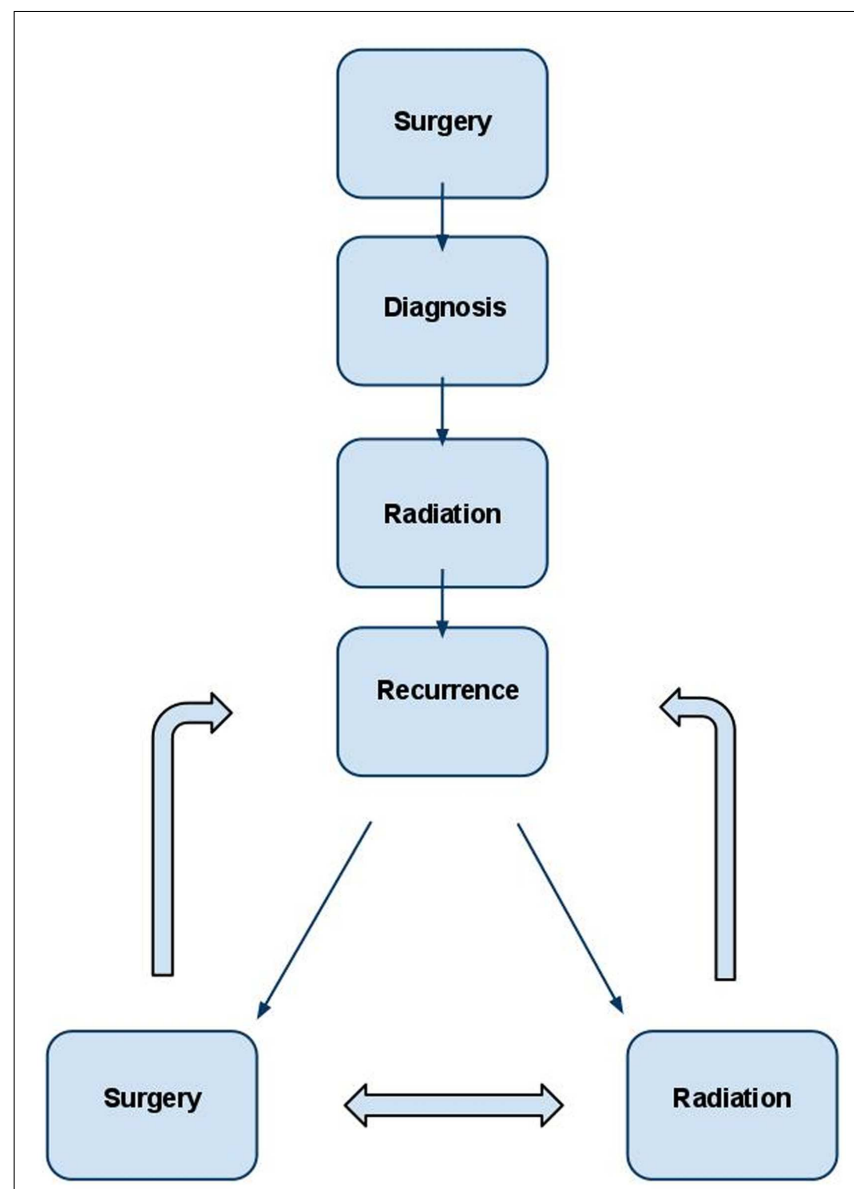

FIGURE 1 | Management strategy for WHO grade II and III meningioma. In the typical patient, diagnosis is first obtained by surgery. Post-operative radiation is administered to decrease the likelihood of recurrence in many cases and almost universally in cases of subtotal resection. If recurrence occurs, retreatment with radiation and/or surgery are both viable options and should be individualized based on the unique clinical scenario.

and non-irradiated patients did not reach statistical significance. For the entire cohort, the actuarial recurrence rates at 1, 5, and 10 years were 7,41 , and $48 \%$, underscoring the propensity of these lesions to recur. Disease-specific survival after first recurrence was 86 and $69 \%$ at 5 and 10 years, respectively.

In comparison to grade II meningiomas, grade III meningiomas have a more dismal prognosis, as illustrated in several case series. In a group of 13 patients with WHO grade III meningiomas who underwent surgical resection, recurrence occurred in $92 \%$ of patients at a time interval of 0.4-2.8 years (29). The 5- and 8year actuarial survival in this group was 47 and $12 \%$, respectively. Only three of the initial cohort received adjuvant radiation therapy following primary resection. In another study of grade III meningiomas, the 5- and 10-year survival rates were found to be slightly higher at 64.3 and $34.5 \%$, respectively (9). Despite the aggressive nature of these tumors, adjuvant radiation therapy is not routinely administered. One survey reported that only 9 of the 56 studied centers recommended radiation after gross total resection of an atypical meningioma (30).

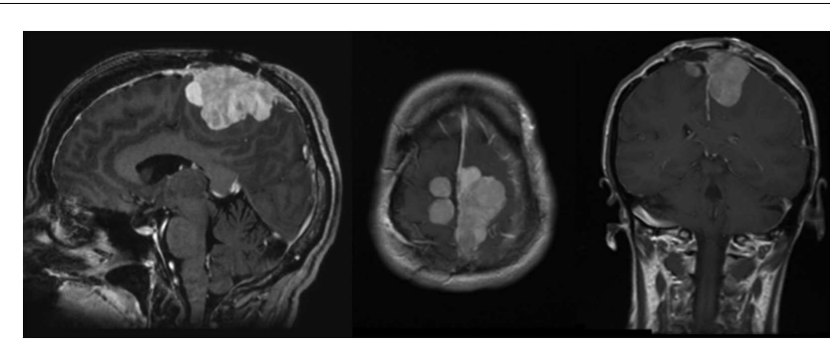

FIGURE 2 | Pre-operative MRI. MRI (I-r, sagittal, axial, coronal) demonstrates an avidly enhancing, complex falcine meningioma involving both sides of the superior sagittal sinus.

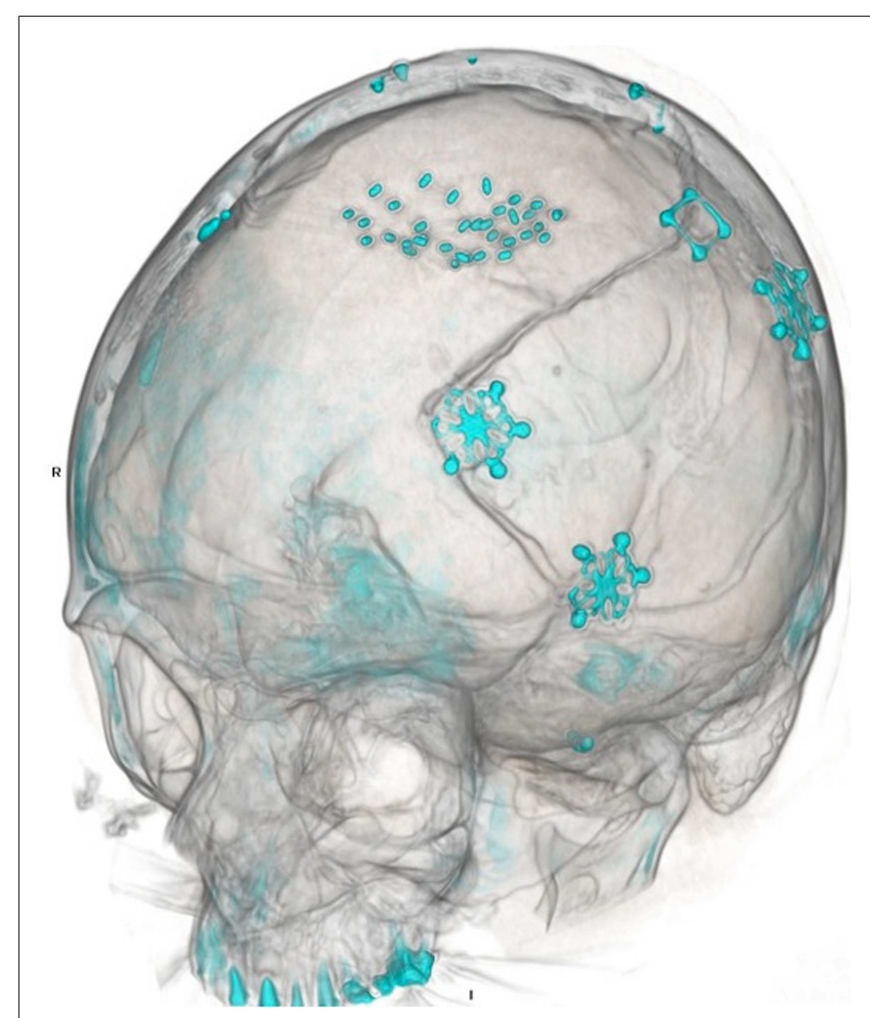

FIGURE 3 | Post-operative CT scan. Three-dimensional reconstruction demonstrates both prior craniotomies with microplate fixation, as well as radioactive brachytherapy seeds placed in the resection cavity.

Undoubtedly, treatment plans for patients are individualized and based on a multitude of factors. Recent elucidation of the genomic landscape of these lesions has identified several genetic subtypes of tumors that may prove to have distinct clinical characteristics and even the potential for response to targeted therapeutics (31-33). Additionally, atypical meningiomas (WHO grade II) with osseous involvement are associated with poorer outcomes. In 47 patients with atypical meningiomas treated at our institution, bony involvement was associated with an increased rate of disease progression and decreased survival (34). Therefore, bone assessment radiographically and histologically is important, and further 

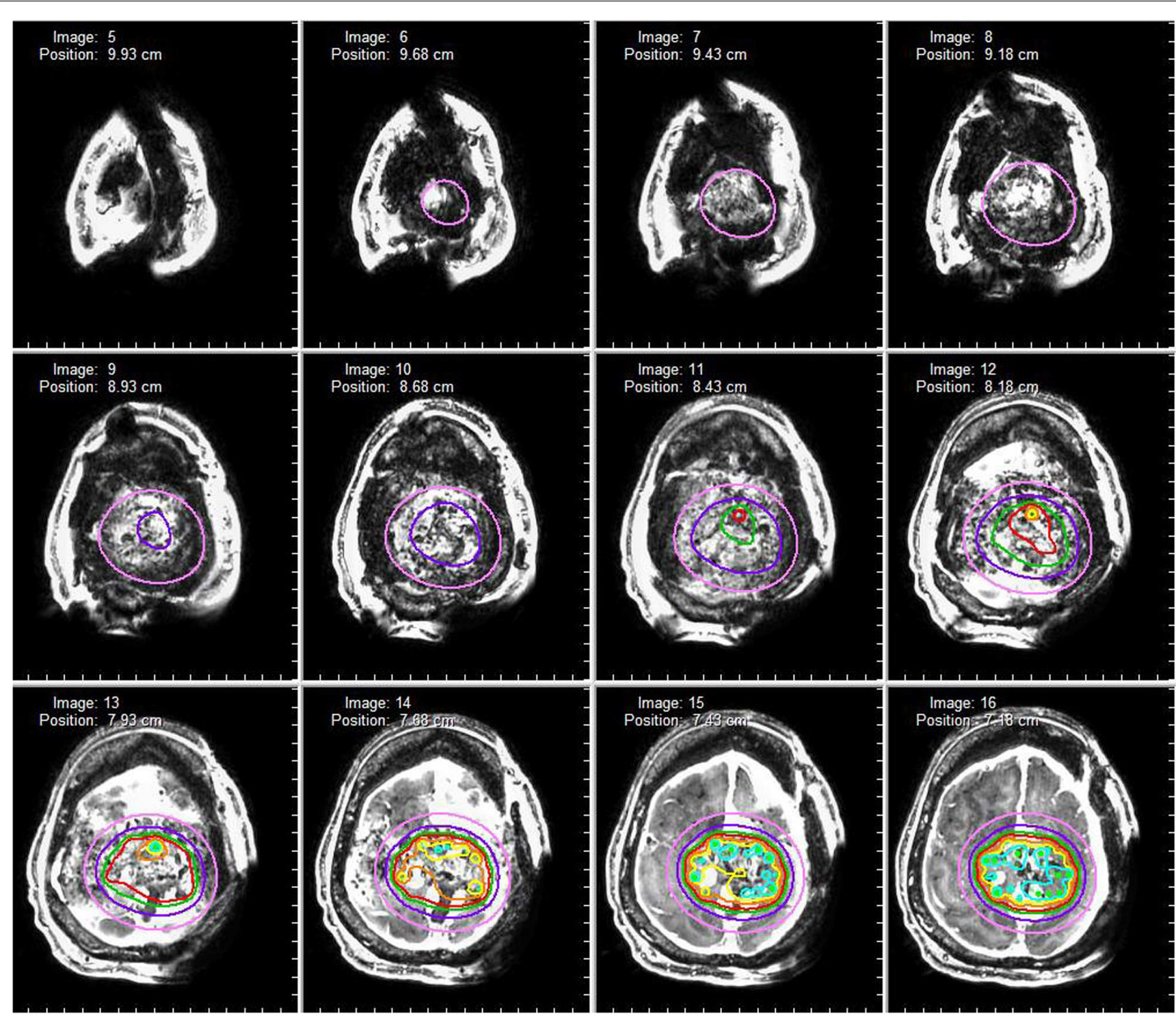

FIGURE 4 | Dosimetry map. A dosimetry map of the radioactive brachytherapy seeds is constructed based on seed arrangement in three-dimensional space. The red isodose line represents a prescription dose $80 \mathrm{~Gy}(80 \%$ isodose level) whereas the pink isodose line represents a prescription dose of $25 \mathrm{~Gy}(25 \%$ isodose).

studies should assess the effectiveness of bone resection and/or targeted radiation therapy to the bone to improve outcome.

\section{BRACHYTHERAPY}

Brachytherapy, the local implantation of a radiation source, is considered "salvage" therapy for the recurrence of aggressive atypical and anaplastic meningiomas. At the time of re-operation, radioactive sources or "seeds" of iodine- 125 are implanted in the resection cavity in an array that generally generates a median total activity of between 20 and $60 \mathrm{mCi}$. Success has been reported with this type of radiation treatment modality, with early reports of two patients with recurrent malignant meningiomas having long term remission after interstitial brachytherapy (35). The largest series to date (21 patients) reported a median survival following implantation of 1.6 years for atypical meningioma and 2.4 years for anaplastic meningioma (36). In this same series, a very high complication rate was reported, with $27 \%$ of patients experiencing radiation necrosis and $27 \%$ with wound complications requiring re-operation.

\section{ONGOING STUDIES}

Several trials are studying the role of radiation therapy in the management of patients with atypical or anaplastic meningiomas. Some studies are evaluating differences in radiation delivery modalities and techniques, such as UPCC 24309 (ClinicalTrials.gov Identifier: NCT01117844). In this trial, outcomes from proton beam therapy will be compared to historical controls associated with conventional photon beam treatment. Other studies aim to determine the efficacy of immediate post-operative radiation 
therapy of meningiomas following resection. One trial conducted by the Radiation Therapy Oncology Group (protocol RTOG 0539, ClinicalTrials.gov Identifier: NCT00895622) is monitoring lowgrade meningiomas (WHO Grade I) with clinical observation following initial surgery, while those with intermediate or high-risk disease (such as all WHO grade II and III meningiomas) receive 6 weeks of radiation therapy using either three-dimensional conformal RT or intensity-modulated radiation therapy.

The other study, run by the European Organization for Research and Treatment of Cancer (protocol EORTC 22042, ClinicalTrials.gov Identifier NCT00626730), has patients with atypical or malignant meningioma being treated with adjuvant radiation therapy following surgical resection. While we eagerly await the

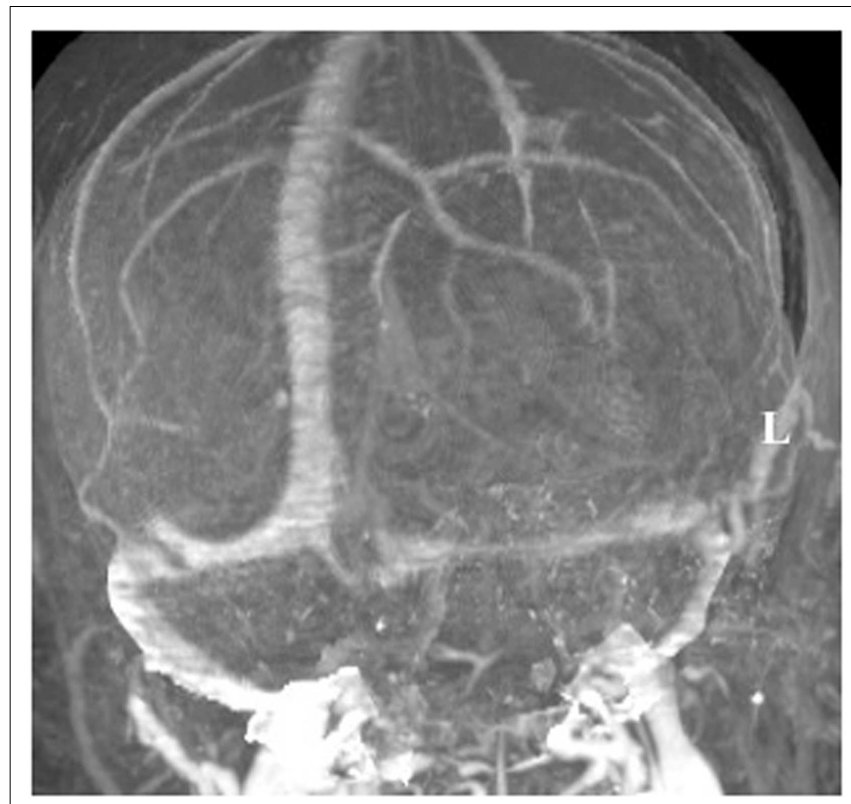

FIGURE 5 | MRI venogram. An MRI venogram demonstrated that the left transverse sinus was atretic and the right transverse sinus was dominant. results of these trials to optimize patient care, current management of patients is based on the best evidence available. While randomized trials do not exist, adjuvant radiation therapy immediately following initial surgery for WHO Grade II and III meningioma should be considered given the high rate of local recurrence (Figure 1). Radiation should also be administered for patients undergoing subtotal resection. These recommendations are congruent with National Comprehensive Cancer Network Clinical Practice Guidelines in Oncology (37).

\section{CASE ILLUSTRATION 1}

A 50-year-old female initially presented 8 years prior with a $5 \mathrm{~cm} \times 5.5 \mathrm{~cm} \times 5 \mathrm{~cm}$ enhancing parasagittal lesion with osseous invasion and left sided motor weakness. She underwent a subtotal resection; the pathological diagnosis was consistent with meningioma WHO grade I with no atypical features and a MIB index of 5\% (38). Postoperatively, her weakness resolved, but 2 months later she was found to have a new nodular enhancing component in the inferior aspect of the resection site measuring $1.5 \mathrm{~cm} \times 1.5 \mathrm{~cm} \times 1.3 \mathrm{~cm}$. She underwent intensity-modulated radiation therapy $6000 \mathrm{cGy}$ without complication. Six years following radiation, she presented with right-sided weakness and was found to have very aggressive interval growth of the residual tumor (Figure 2). Given the suspicion that her tumor had undergone either atypical or anaplastic transformation, she underwent subtotal resection and placement of interstitial brachytherapy I(125) seeds (Figures 3 and 4). Pathological diagnosis of the tumor removed at the time of the second surgery revealed an atypical meningioma, WHO Grade II of III with high cell density, architectural sheeting, and prominent nucleoli. This case highlights the unique scenario of tumor of progression following treatment. When atypical or malignant progression is suspected on preoperative imaging, brachytherapy can be considered at the time of re-operation.

\section{CASE ILLUSTRATION 2}

A 60-year-old woman underwent gross total resection of her right frontal convexity meningioma; and received post-operative
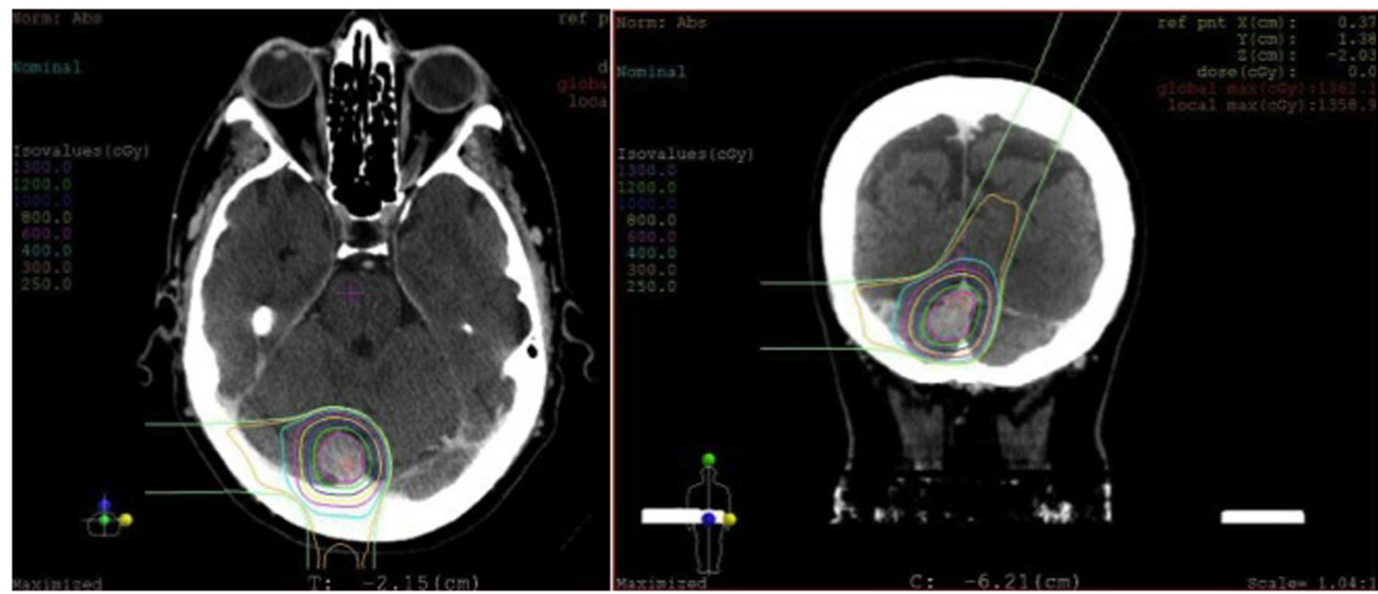

FIGURE 6 | Radiosurgery dosimetry. Dosimetry map for proton radiosurgical treatment of a torcular meningioma. 
radiation for the pathological diagnosis of atypical meningioma. Two years later on routine follow-up, she was found to have a new lesion invading the torcula. An MRI venogram was obtained that demonstrated an unfavorable dural sinus configuration; her left transverse sinus was atretic and her right transverse sinus was dominant (Figure 5).

In weighing the risks and benefits of open surgery versus stereotactic radiosurgery, it was decided that radiosurgery would be the best treatment option for her. She underwent stereotactic radiosurgery to the lesion, presumed to be an atypical meningioma based on her previously pathology from the first surgery (Figure 6). From a technical aspect, given the sinus involvement on pre-operative imaging, it was likely that a gross total resection

\section{REFERENCES}

1. Louis DN, Ohgaki H, Wiestler OD, Cavenee WK, Burger PC, Jouvet A, et al. The 2007 WHO classification of tumours of the central nervous system. Acta Neuropathol (2007) 114(2):97-109. doi:10.1007/ s00401-007-0243-4

2. Aghi MK, Carter BS, Cosgrove GR, Ojemann RG, Amin-Hanjani $S$, Martuza RL, et al. Long-term recurrence rates of atypical meningiomas after gross total resection with or without postoperative adjuvant radiation. Neurosurgery (2009) 64(1):56-60. doi:10.1227/01.NEU. 0000330399.55586 .63

3. Stafford SL, Perry A, Suman VJ, Meyer FB, Scheithauer BW, Lohse CM, et al., editors. Primarily resected meningiomas: outcome and prognostic factors in 581 Mayo Clinic patients, 1978 through 1988. Mayo Clinic Proceedings; Rochester: Elsevier (1998). p. 936-42.

4. Goyal LK, Suh JH, Mohan DS, Prayson RA, Lee J, Barnett GH. Local control and overall survival in atypical meningioma: a retrospective study. Int J Radiat Oncol Biol Phys (2000) 46(1):57. doi:10.1016/ S0360-3016(99)00349-1

5. Coke CC, Corn BW, Werner-Wasik M, Xie Y, Curran WJ Jr. Atypical and malignant meningiomas: an outcome report of seventeen cases. J Neurooncol (1998) 39(1):65-70. doi:10.1023/A:1005981731739

6. Yang S-Y, Park C-K, Park S-H, Kim DG, Chung YS, Jung H-W. Atypical and anaplastic meningiomas: prognostic implications of clinicopathological features. J Neurol Neurosurg Psychiatry (2008) 79(5):574-80. doi:10.1136/jnnp.2007.121582

7. Pasquier D, Bijmolt S, Veninga T, Rezvoy N, Villa S, Krengli M, et al. Atypical and malignant meningioma: outcome and prognostic factors in 119 irradiated patients. A multicenter, retrospective study of the Rare Cancer Network. Int J Radiat Oncol Biol Phys (2008) 71(5):1388-93. doi:10.1016/ j.ijrobp.2007.12.020

8. Perry A, Scheithauer BW, Stafford SL, Lohse CM, Wollan PC. "Malignancy" in meningiomas. Cancer (1999) 85(9):2046-56. doi:10.1002/(SICI) 1097-0142(19990501)85:9<2046: :AID-CNCR23>3.0.CO;2-M

9. Palma L, Celli P, Franco C, Cervoni L, Cantore G. Long-term prognosis for atypical and malignant meningiomas: a study of 71 surgical cases. J Neurosurg (1997) 86(5): 793-800. doi:10.3171/jns.1997.86. 5.0793

10. Dziuk TW, Woo S, Butler EB, Thornby J, Grossman R, Dennis WS, et al. Malignant meningioma: an indication for initial aggressive surgery and adjuvant radiotherapy. J Neurooncol (1998) 37(2):177-88. doi:10.1023/A:1005853720926

11. Hug EB, DeVries A, Thornton AF, Munzenrider JE, Pardo FS, HedleyWhyte ET, et al. Management of atypical and malignant meningiomas: role of high-dose, 3Dconformal radiation therapy. $J \mathrm{Neu}$ rooncol (2000) 48(2):151-60. doi: 10.1023/A:1006434124794

12. Milosevic M, Frost P, Laperriere N, Wong C, Simpson W. Radiotherapy for atypical or malignant intracranial meningioma. Int J Radiat Oncol Biol Phys (1996) 34(4):817. doi:10. 1016/0360-3016(95)02166-3

13. Kano H, Takahashi JA, Katsuki T, Araki N, Oya N, Hiraoka M, et al. Stereotactic radiosurgery for atypical and anaplastic meningiomas. J Neurooncol (2007) 84(1): 41-7. doi:10.1007/s11060-0079338-y

14. Huffmann BC, Reinacher PC, Gilsbach JM. Gamma knife surgery for atypical meningiomas. J Neurosurg (2005) 102:283-6. doi:10.3171/jns. 2005.102.s_supplement.0283

would not be able to be achieved and any tumor left remaining on the sinus would need to be treated with radiation, regardless. Stereotactic radiosurgery provides the benefit of treating the entire lesion while minimizing the risk of a potentially catastrophic venous infarct or hemorrhage associated with open surgery.

\section{CONCLUSION}

World Health Organization grade II and III meningiomas can have a malignant clinical course. Multidisciplinary strategies of care involving aggressive surgical resection and post-operative radiation therapy may reduce recurrence rates. Studies to assess the optimal timing and modality of post-operative radiation are underway.

15. Pollock BE, Stafford SL, Link MJ, Garces YI, Foote RL. Stereotactic radiosurgery of World Health Organization grade II and III intracranial meningiomas. Cancer (2012) 118(4):1048-54. doi:10.1002/cncr. 26362

16. Harris AE, Lee JY, Omalu B, Flickinger JC, Kondziolka D, Lunsford LD, et al. The effect of radiosurgery during management of aggressive meningiomas. Surg Neurol (2003) 60(4):298-305. doi: 10.1016/S0090-3019(03)00320-3

17. Girvigian MR, Chen JC, Rahimian J, Miller MJ, Tome M. Comparison of early complications for patients with convexity and parasagittal meningiomas treated with either stereotactic radiosurgery or fractionated stereotactic radiotherapy. Neurosurgery (2008) 62(5):A19-28. doi:10.1227/01.neu.0000325933. 34154.cb

18. Unger KR, Lominska CE, Chanyasulkit J, Randolph-Jackson P, White RL, Aulisi E, et al. Risk factors for post treatment edema in patients treated with stereotactic radiosurgery for meningiomas. Neurosurgery (2012) 70(3):639-45. doi: 10.1227/NEU.0b013e3182351ae7

19. Weber DC, Schneider R, Goitein G, Koch T, Ares C, Geismar JH, et al. Spot scanning-based proton therapy for intracranial meningioma: long-term results from the Paul Scherrer Institute. Int J Radiat Oncol Biol Phys (2012) 83(3):865-71. doi: 10.1016/j.ijrobp.2011.08.027

20. Combs S, Edler L, Burkholder I, Rieken S, Habermehl D, Jäkel O, et al. Treatment of patients with atypical meningiomas Simpson grade 4 and 5 with a carbon ion boost in combination with postoperative photon radiotherapy: the MARCIE trial. BMCCancer (2010) 10(1):615. doi:10.1186/1471-2407-10-615

21. Combs SE, Hartmann C, Nikoghosyan A, Jäkel O, Karger
$\mathrm{CP}$, Haberer $\mathrm{T}$, et al. Carbon ion radiation therapy for high-risk meningiomas. Radiother Oncol (2010) 95(1):54-9. doi:10.1016/j.radonc.2009.12.029

22. Boskos C, Feuvret L, Noel G, Habrand J-L, Pommier P, Alapetite $\mathrm{C}$, et al. Combined proton and photon conformal radiotherapy for intracranial atypical and malignant meningioma. Int $\mathrm{J}$ Radiat Oncol Biol Phys (2009) 75(2):doi:10.1016/ j.ijrobp.2008.10.053

23. Cai R, Barnett GH, Novak E, Chao ST, Suh JH. Principal risk of peritumoral edema after stereotactic radiosurgery for intracranial meningioma is tumor-brain contact interface area. Neurosurgery (2010) 66(3):513-22. doi:10.1227/01.NEU. 0000365366.53337 .88

24. Kan P, Liu JK, Wendland MM, Shrieve D, Jensen RL. Peritumoral edema after stereotactic radiosurgery for intracranial meningiomas and molecular factors that predict its development. J Neurooncol (2007) 83(1):33-8. doi:10.1007/ s11060-006-9294-y

25. Patil CG, Hoang S, Borchers IIIDJ, Sakamoto G, Soltys SG, Gibbs IC, et al. Predictors of peritumoral edema after stereotactic radiosurgery of supratentorial meningiomas. Neurosurgery (2008) 63(3):435-42. doi:10.1227/01.NEU. 0000325257.58684 .92

26. Stafford SL, Pollock BE, Leavitt JA, Foote RL, Brown PD, Link $\mathrm{MJ}$, et al. A study on the radiation tolerance of the optic nerves and chiasm after stereotactic radiosurgery. Int $J$ Radiat Oncol Biol Phys (2003) 55(5):1177. doi:10. 1016/S0360-3016(02)04380-8

27. Ganz J, Reda W, Abdelkarim K. Adverse radiation effects after Gamma Knife Surgery in relation to dose and volume. Acta $\mathrm{Neu}$ rochir (2009) 151(1):9-19. doi:10. 1007/s00701-008-0174-4 
28. Kleihues P, Burger PC, Scheithauer BW. The new WHO classification of brain tumours. Brain Pathol (1993) 3(3):255-68. doi:10.1111/j. 1750-3639.1993.tb00752.x

29. Rosenberg LA, Prayson RA, Lee J, Reddy C, Chao ST, Barnett GH, et al. Long-term experience with World Health Organization grade III (malignant) meningiomas at a single institution. Int $J$ Radiat Oncol Biol Phys (2009) 74(2): 427-32. doi:10.1016/j.ijrobp.2008. 08.018

30. Simon M, Boström J, Koch P, Schramm J. Interinstitutional variance of postoperative radiotherapy and follow up for meningiomas in Germany: impact of changes of the WHO classification. J Neurol Neurosurg Psychiatry (2006) 77(6):767-73. doi:10.1136/ jnnp.2005.077974

31. Brastianos PK, Horowitz PM, Santagata S, Jones RT, McKenna A, Getz $G$, et al. Genomic sequencing of meningiomas identifies oncogenic SMO and AKT1 mutations.
Nat Genet (2013). 45(3):285-9. doi: 10.1038/ng.2526

32. Clark VE, Erson-Omay EZ, Serin A, Yin J, Cotney J, Özduman K, et al. Genomic analysis of non-NF2 meningiomas reveals mutations in TRAF7, KLF4, AKT1, and SMO. Science (2013) 339(6123):1077-80. doi:10.1126/science.1233009

33. Gao F, Shi L, Russin J, Zeng L, Chang X, He S, et al. DNA methylation in the malignant transformation of meningiomas. PLoS ONE (2013) 8(1):e54114. doi:10.1371/ journal.pone.0054114

34. Gabeau-Lacet D, Aghi M, Betensky RA, Barker FG, Loeffler JS, Louis DN. Bone involvement predicts poor outcome in atypical meningioma. $J$ Neurosurg (2009) 111(3):464. doi:10.3171/2009.2.JNS08877

35. Gutin PH, Leibel SA, Hosobuchi Y, Crumley RL, Edwards MS, Wilson CB, et al. Brachytherapy of recurrent tumors of the skull base and spine with iodine-125 sources. Neurosurgery (1987) 20(6):938-45. doi:10.1227/00006123-19870600000020

36. Ware ML, Larson DA, Sneed PK, Wara WW, McDermott MW Surgical resection and permanent brachytherapy for recurrent atypical and malignant meningioma. Neurosurgery (2004) 54(1):55-64. doi:10.1227/01.NEU.0000097199. 26412.2A

37. Brem SS, Bierman PJ, Brem $\mathrm{H}$ Butowski N, Chamberlain MC, Chiocca EA, et al. Central nervous system cancers. J Natl Compr Canc Netw (2011) 9(4):352-400.

38. Perry A, Stafford SL, Scheithauer BW, Suman VJ, Lohse CM. The prognostic significance of MIB-1, p53, and DNA flow cytometry in completely resected primary meningiomas. Cancer (1998) 82(11):2262-9. doi:10.1002/(SICI) 1097-0142(19980601)82:11<2262: :AID-CNCR23>3.0.CO;2-R

Conflict of Interest Statement: The authors declare that the research was conducted in the absence of any commercial or financial relationships that could be construed as a potentia conflict of interest.

Received: 28 June 2013; paper pending published: 26 July 2013; accepted: 16 August 2013; published online: 02 September 2013.

Citation: Walcott BP, Nahed BV, Brastianos PK and Loeffler JS (2013) Radiation treatment for WHO grade II and III meningiomas. Front. Oncol. 3:227. doi: 10.3389/fonc.2013.00227

This article was submitted to Radiation Oncology, a section of the journal Frontiers in Oncology.

Copyright (C) 2013 Walcott, Nahed, Brastianos and Loeffler. This is an open-access article distributed under the terms of the Creative Commons Attribution License (CC BY). The use, distribution or reproduction in other forums is permitted, provided the original author(s) or licensor are credited and that the original publication in this journal is cited, in accordance with accepted academic practice. No use, distribution or reproduction is permitted which does not comply with these terms. 